\title{
The Role of Low-Intensity Biostimulation Laser Therapy in Transforming Growth Factor $\beta 1$, Bone Alkaline Phosphatase and Osteocalcin Expression during Orthodontic Tooth Movement in Cavia porcellus
}

\author{
Ida Bagus Narmada ${ }^{1}$ \\ Muhammad Rubianto² \\ ${ }^{1}$ Department of Orthodontics, Faculty of Dental Medicine, \\ Airlangga University, Surabaya, Indonesia \\ 2Department of Periodontics, Faculty of Dental Medicine, \\ Airlangga University, Surabaya, Indonesia \\ ${ }^{3}$ Department of Pathology Anatomy, Faculty of Medicine, \\ Airlangga University, Surabaya, Indonesia
}

Suhartono Taat Putra ${ }^{3}$

\begin{abstract}
Address for correspondence Ida Bagus Narmada, Department of Orthodontics, Faculty of Dental Medicine, Airlangga University, Surabaya, Indonesia (e-mail: ida-b-n@fkg.unair.ac.id).
\end{abstract}

Eur J Dent 2019;13:102-107

\begin{abstract}
Keywords

- bone alkaline

phosphatase

- irradiation low-

intensity laser therapy

- orthodontic tooth

movement

- osteocalcin,

transforming growth

factor $\beta 1$

Objective The aim of this study is to analyze the low-intensity laser therapy (LILT) biostimulation mechanism as adjuvant therapy within orthodontic treatment as a means of accelerating bone remodeling by transforming growth factor $\beta 1$ (TGF- $\beta 1$ ), bone alkaline phosphatase (BALP), and osteocalcin (OSC) expression.

Materials and Methods An analytical experimental method incorporating a posttest only randomized the control group design. The sample consisted of 24 3- to 4-monthold male Cavia porcellus weighing between 300 and $500 \mathrm{~g}$ divided into three groups (group 1: control, group 2: received orthodontic treatment, and group 3: received orthodontic treatment with irradiation LILT). LILT biostimulation at a dose of 4 joule $/ \mathrm{cm}^{2}$ was performed daily for $3 \mathrm{~min}$ on the mesial-distal labial-palatal of the first dextra and sinistra incisor for 2 weeks. The TGF- $\beta 1$, BALP, and OSC expression was subjected to immunohistochemical analysis. An analysis of variance with multiple comparison, a Tukey's honestly significant difference test, a Kruskal-Wallis test, and a WilcoxonMann-Whitney test were all performed $(p<0.05)$.

Results TGF- $\beta 1$ expression was significantly different $(p=0.047 ; p<0.05)$ in the tension area, but not in the compression side $(p=0.154 ; p>0.05)$. BALP expression was significantly different in both the tension $(p=0.009)$ and compression areas $(p=0.005 ; p<0.05)$. OSC expression was significantly different $(p=0.034 ; p<0.05)$ in the tension side, but not in the compression area $(p=1.194 ; p>0.05)$.

Conclusion LILT biostimulation can increase TGF- $\beta 1$, BALP, and OSC expression during orthodontic tooth movement.
\end{abstract}

\section{Introduction}

Malocclusion incidence varies between individuals and population groups in features such as protrusion and cross bite that may affect dentofacial esthetics. These, in turn, can influence orofacial development, sociopsychological esteem, temporomandibular disorder, and pain, thus decreasing the quality of life of the patient. ${ }^{1-4}$
The prevalence of malocclusion based on the index of orthodontic treatment need (IOTN) in the United Kingdom averages $45 \%$ in 12 -year-old children and $15 \%$ in those aged 15 years. The prevalence of malocclusion in the United States, according to the IOTN, is $42 \%$ in Caucasian teenagers and $30 \%$ in their African-American counterparts aged 12-17 years. ${ }^{5,6}$ Malocclusion is ranked the third most prevalent dental and 
oral health problem in Indonesia after caries and gingivitis at about $90 \%{ }^{7-9}$

The goal of orthodontic treatment is to align the teeth in a correct dental arch as a means of maximizing efficient chewing, facial harmony, oral tissue health, dentofacial esthetics, and posttreatment posture stability. Such orthodontic treatment requires approximately 2-3 years to complete which represents a burden for the patient. ${ }^{10}$ Prolonged orthodontic treatment with fixed appliances of such duration is common within the community and may increase the risk of gingivitis, tooth resorption, and dental caries. ${ }^{11}$ Orthodontic tooth movement is caused by the orthodontic mechanical stress, the treatment of which can be accelerated by increased bone remodeling during the treatment. Prostaglandins (PGE2), 1.25-dihydroxivitamin D3 [1.25- $(\mathrm{OH}) 2 \mathrm{D} 3]$, and parathyroid hormone $(\mathrm{PTH})$, together with ultrasonic waves and osteocalcin (OSC) surrounding the tooth, have been used to accelerate the bone remodeling. However, the results have not been as anticipated. ${ }^{11-13}$

Orthodontic treatment applies mechanical force as a means of stressing cells which can cause inflammation. Activated inflammatory cells, especially macrophages and neutrophils, produce various inflammatory cytokines such as PGE, interleukin-1 (IL-1), IL-6, and tumor necrosis factor $\alpha($ TNF- $\alpha)$. Osteoclast differentiation by means of receptor activator of nuclear factor $\kappa \mathrm{B}$ (RANK) and RANK ligand can be identified through analysis of the gingival crevicular fluid. ${ }^{14,15}$

Alveolar bone remodeling involves bone resorption by osteoclast and bone deformation by osteoblasts. Bone remodeling involving the expression of transforming growth factors $\beta-1$ (TGF- $\beta 1$ ) increased between days 3 and 6 , whereas the tension area inhibited osteoclast activity. Fibroblasts stimulate collagen synthesis to produce extracellular matrices. Osteoblasts play a direct role in the tooth movement mechanism through bone formation by triggering various noncollagen proteins, growth factors (GFs), and bone morphogenetic protein (BMP). OSC is a noncollagen protein produced specifically by osteoblasts that plays an important role as a mineralization regulator and is a more specific biochemical marker of osteoblast activity than bone alkaline phosphatase (BALP). ${ }^{16-18}$

This study sought to analyze the irradiation mechanism of low-intensity laser therapy, as an adjuvant therapy in orthodontic treatment, employed to accelerate the bone remodeling through TGF- $\beta 1$, BALP, and OSC expression.

\section{Materials and Methods}

The study protocol was approved by the Health Research Ethical Clearance Commission, Faculty of Dental Medicine, Airlangga University (number: 53/KKEPK. FKG/VIII/2009) and constituted a laboratory experiment with posttest only control group design. The sample groups were selected by random sampling method. The samples consisted of 24 male Cavia porcellus (marmots) which were 3-4 months old and 300-500 g in weight, with good oral health as confirmed by a veterinarian. The sample size required for each group was eight. The sample divided into three groups; group 1: the control group; group 2 (SM): mechanical stressors directly attached to the maxillary incisors by single orthodontic brackets on the labial surfaces and a close coil nickel titanium (NiTi) spring at $10 \mathrm{~g}$ of pressure then inserted; and group 3 (SM-L): mechanical stressors directly attached to the maxillary incisors by single orthodontic brackets on the labial surfaces, a close coil NiTi spring at $10 \mathrm{~g}$ of pressure then inserted and LILT irradiation of 4 joules $/ \mathrm{cm}^{2}$ in the mesial-distal and labial-palatal regions. The duration of LILT irradiation was 3 min per point each day. The duration of treatment was 2 weeks (day 0 to day 14).

The cages of the participants were washed and disinfected 1 week before initiation of the experiment. The male marmot participants underwent a 1-week period of adaptation to the laboratory. They were then anesthetized with $50 \mathrm{mg} / \mathrm{kg}$ of intraperitoneal pentobarbital sodium anesthesia before the application of orthodontic mechanical stressor NiTi springs. The participants were all subsequently sacrificed by means of a lethal intraperitoneal dose of anesthesia sodium pentobarbital. The maxilla of the participants was resected along with the teeth to obtain gingiva tissue, periodontal ligament, and alveolar bone before the conducting of a histology pathology anatomy (HPA) examination.

Hematoxylin-eosin staining was performed for the purposes of a HPA examination. Immunohistochemical (IHC) analysis was performed to detect TGF- $\beta 1$, BALP, and OSC expression using anti-TGF- $\beta 1$ monoclonal antibodies (3C11 sc-130348), antialkaline phosphatase (ALP) (B-10 sc-365765), and anti-OSC (c-7 sc-376726) (Santa Cruz Biotechnology, Inc., Dallas, Texas, USA). The IHC slide was observed through a light microscope (Leica SCN400) at $\times 400$ as part of the calculation process.

Data analysis was performed on the TGF- $\beta$, BALP, and OSC expression results in each group by analyzing the mean and standard deviations. A normality test (Kolmogorov-Smirnov test) was performed on all groups. The homogeneous variance between groups was analyzed by a Levene's test $(p>0.05)$. An analysis of variance was performed, followed by a Tukey's honestly significant difference test and a multiple comparison test, to analyze the differences between the groups. A Kruskal-Wallis test was performed in cases where the data were abnormally distributed, whereas a group Wilcoxon-Mann-Whitney analysis was performed to analyze the differences between groups $(p<0.05)$.

\section{Results}

All data were normally distributed $(p>0.05)(-$ Table 1$)$. Positive TGF- $\beta 1$ expression was obtained from the observation of periodontal ligament fibroblast cells. TGF- $\beta 1$ expression featured strong positive color reactions (brown color) in Group III ( - Fig. 1). Group III had the highest average TGF- $\beta 1$ expression ( - Fig. 2 ).

TGF- $\beta 1$ expression revealed homogeneous variance $(p=0.874 ; p>0.05)$ and normal distribution $(p=0.001$; 
Table 1 Kolmogorov-Smirnov normal distribution test results for control group (K), mechanical stress (SM and mechanical stress + low-intensity laser therapy [SM-L]) on the tensile and compression sides

\begin{tabular}{|l|l|l|l|l|}
\hline \multirow{2}{*}{ Side } & Variable & $\boldsymbol{p}$ (each group) & \multicolumn{2}{l|}{} \\
\cline { 3 - 5 } & & $\mathrm{K}$ & $\mathrm{SM}$ & $\mathrm{SM}+\mathrm{L}$ \\
\hline Tension & $\sum$ cell & $0.200^{*}$ & $0.200^{*}$ & $0.200^{*}$ \\
\hline Compression & TGF $-\beta 1$ & 0.001 & $0.200^{*}$ & $0.200^{*}$ \\
\hline Tension & $\sum$ cell & 0.001 & $0.200^{*}$ & $0.200^{*}$ \\
\hline Compression & BALP & $0.200^{*}$ & $0.200^{*}$ & $0.200^{*}$ \\
\hline Tension & $\sum$ cell & $0.200^{*}$ & $0.200^{*}$ & $0.200^{*}$ \\
\hline Compression & Osteocalcin & $0.200^{*}$ & $0.200^{*}$ & 0.110 \\
\hline
\end{tabular}

Abbreviations: BALP, bone alkaline phosphatase; TGF, transforming growth factor.

*Significant $(p>0.05)$.

$p>0.05)$ between the groups. LILT irradiation increased TGF- $\beta 1$ expression in the compression side ( - Table 2 ) and tension side (-Table 3 ). There is a difference in TGF- $\beta 1$ expression between groups in the tension side $(p=0.047$; $p<0.05$ ), whereas no statistically significant difference

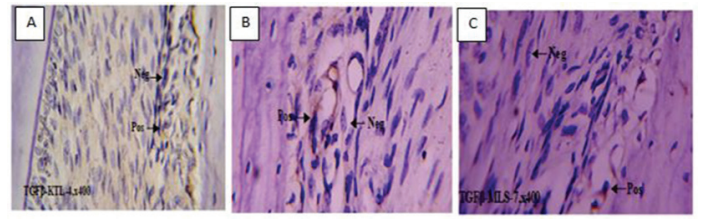

Fig. 1 Transforming growth factor- $\beta$ expression (arrow) in the periodontal ligament fibroblast cells of a marmot (Cavia porcellus). (a) Transforming growth factor- $\beta$ control group. (b) Transforming growth factor- $\beta$ mechanical stress. (c) Transforming growth factor- $\beta$ mechanical stress + low-intensity laser therapy. Positive transforming growth factor- $\beta$ expression is represented by the brown coloration on the tensile and pressure area at $\times 400$.
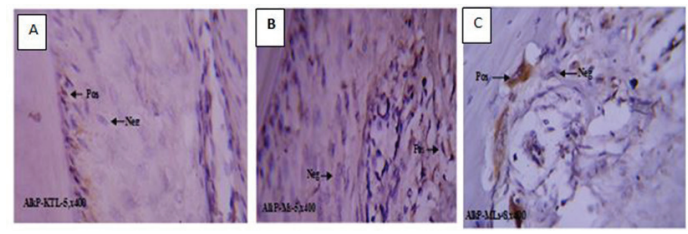

Fig. 2 Bone alkaline phosphatase expression (arrow) in the periodontal ligament fibroblast of a marmot (Cavia porcellus). (a) Bone alkaline phosphatase normal control. (b) Bone alkaline phosphatase mechanical stress. (c) Bone alkaline phosphatase mechanical stress + low-intensity laser therapy. Bone alkaline phosphatase positive expression is indicated by the brown areas on the tensile and pressure area at $\times 400$. existed in TGF- $\beta 1$ expression between groups in the compression side $(p=0.154 ; p>0.05)$.

BALP positive activation expression was obtained from the observations of periodontal ligament fibroblast cells with stronger positive color reaction (brown) in group 3 than in the control group ( $\mathbf{- F i g}$. 3). Group 3 had the highest average BALP expression. The BALP expression in the compression side demonstrated the homogeneous variances between the groups ( $p=2.599$; $p>0.05)$. There was a difference in BALP expression between the compression side ( $p=0.009 ; p<0.05)$. LILT irradiation increased BALP expression in the compression side (-Table 4). The BALP expression in the tension side had a nonhomogeneous variance between the groups $(p=0.432 ; p<0.05)$. There were significant differences in BALP expression in the tension side between the groups $(p=0.005 ; p<0.05)$ (-Table 5).

The positive activation expression of OSC was confirmed by observation of the periodontal ligament fibroblast cells of the marmot (Cavia porcellus) which produced a positive light brown reaction in group 3 compared to that of the
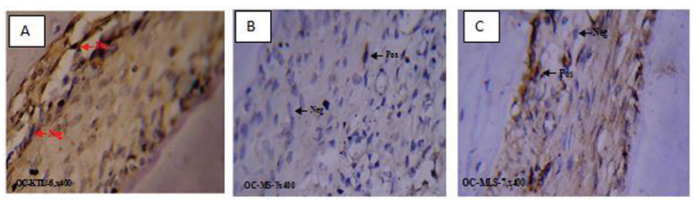

Fig. 3 Osteocalcin expression (arrow) in the periodontal ligament fibroblast cells of marmots (Cavia porcellus). (a) Osteocalcin control. (b) Osteocalcin mechanical stress. (c) Ostecalcin mechanical stress + low-intensity laser therapy. Positive osteocalcin expression is characterized by brown coloration on the tensile and pressure area at $\times 400$.

Table 2 Analysis of variance test result and transforming growth factor $\beta 1$ expression result in the tension side between groups

\begin{tabular}{|c|c|c|c|c|c|c|}
\hline \multirow[t]{2}{*}{ Group } & \multirow[t]{2}{*}{$n$} & \multicolumn{4}{|c|}{$\sum$ Positive cell of TGF- $\beta_{1}$ pull } & \multirow[t]{2}{*}{ ANOVA } \\
\hline & & Mean & SD & Minimum & Maximum & \\
\hline Control & 8 & 1.75 & 1.282 & 0 & 3 & $F=3.560$ \\
\hline SM & 8 & 3.38 & 1.598 & 1 & 6 & $p=0.047^{*}$ \\
\hline SM-L & 8 & 3.88 & 2.031 & 1 & 7 & \\
\hline
\end{tabular}

Abbreviations: ANOVA, analysis of variance; SD, standard deviation; TGF, transforming growth factor.

*Significant $(p<0.05)$. 
control group. The control group demonstrated a higher average OSC expression in the tension and compression side than group III. The OSC expression in the tension side demonstrated homogeneous variance $(p=2.842 ; p>0.05)$. There was significant difference in OSC expression in the tension side $(p=0.034 ; p<0.05)$ ( - Table 6). OSC expression in the compression side demonstrated nonhomogeneous variance $(p=0.017 ; p<0.05)$ ( - Table 7$)$. There was no significant difference in OSC expression in the compression side $(p=0.194 ; p>0.05)$.

Table 3 Kruskal-Wallis test result and transforming growth factor $\beta 1$ expression result in the compression side between groups

\begin{tabular}{|l|l|l|l|l|l|l|}
\hline \multirow{2}{*}{ Group } & $\boldsymbol{n}$ & \multicolumn{4}{|c|}{$\sum$ Positive cells of TGF- $\beta_{1}$ tension } & \multirow{2}{*}{ Kruskal-Wallis test } \\
\cline { 3 - 7 } & & Mean ranks & SD & Minimum & Maximum & \\
\hline Control & 8 & 9.00 & 0.518 & 1 & 2 & $\chi^{2}, F=3.739$ \\
\hline SM & 8 & 13.00 & 4.121 & 1 & 5 & $p=0.154$ \\
\hline SM-L & 8 & 15.50 & 4.549 & 1 & 6 & \\
\hline
\end{tabular}

Abbreviations: SD, standard deviation; TGF, transforming growth factor.

Not significant $(p>0.05)$.

Table 4 Analysis of variance result of bone alkaline phosphatase expression in the compression side between groups

\begin{tabular}{|c|c|c|c|c|c|c|}
\hline \multirow[t]{2}{*}{ Treatment group } & \multirow[t]{2}{*}{$n$} & \multicolumn{4}{|c|}{$\sum$ Positive cell of BALP pressure } & \multirow[t]{2}{*}{ ANOVA } \\
\hline & & Mean & SD & Minimum & Maximum & \\
\hline Control & 8 & 1.00 & 0.926 & 0 & 2 & $F=5.942$ \\
\hline SM & 8 & 5.50 & 3.024 & 2 & 12 & $p=0.009 *$ \\
\hline SM-L & 8 & 3.75 & 3.75 & 0 & 9 & \\
\hline
\end{tabular}

Abbreviations: ANOVA, analysis of variance; BALP, bone alkaline phosphatase; SD, standard deviation.

* Significant $(p<0.05)$.

Table 5 Test results of bone alkaline phosphatase expression in the tension side between groups

\begin{tabular}{|c|c|c|c|c|c|c|}
\hline \multirow[t]{2}{*}{ Treatment group } & \multirow[t]{2}{*}{$n$} & \multicolumn{4}{|c|}{$\sum$ Positive cell BALP pull } & \multirow[t]{2}{*}{ Kruskal-Wallis test } \\
\hline & & Mean & SD & Minimum & Maximum & \\
\hline Control & 8 & 6.00 & 1.690 & 0 & 5 & $\chi^{2}, F=10.596$ \\
\hline SM & 8 & 16.69 & 4.121 & 2 & 15 & $p=0.005^{*}$ \\
\hline SM-L & 8 & 14.81 & 4.549 & 0 & 13 & \\
\hline
\end{tabular}

Abbreviations: BALP, bone alkaline phosphatase; SD, standard deviation.

* Significant $(p<0.05)$.

Table 6 Analysis of variance results for the osteocalcin expression in the tension side between groups

\begin{tabular}{|c|c|c|c|c|c|c|}
\hline \multirow[t]{2}{*}{ Treatment group } & \multirow[t]{2}{*}{$N$} & \multicolumn{4}{|c|}{$\sum$ Positive cell of osteocalcin traction } & \multirow[t]{2}{*}{ ANOVA } \\
\hline & & Mean & SD & Minimum & Maximum & \\
\hline Control & 8 & 20.00 & 12.501 & 0 & 35 & $F=3.982$ \\
\hline SM & 8 & 9.13 & 4.121 & 3 & 15 & $p=0.034^{*}$ \\
\hline SM-L & 8 & 19.25 & 7.005 & 8 & 28 & \\
\hline
\end{tabular}

Abbreviations: ANOVA, analysis of variance; SD, standard deviation.

* Significant $(p<0.05)$.

Table 7 Independent t-test results for osteocalcin expression in the compression side between groups

\begin{tabular}{|c|c|c|c|c|c|c|}
\hline \multirow[t]{2}{*}{ Treatment group } & \multirow[t]{2}{*}{$N$} & \multicolumn{4}{|c|}{$\sum$ Positive cell of osteocalcin in the pressure area } & \multirow[t]{2}{*}{$t$-test } \\
\hline & & Mean & SD & Minimum & Maximum & \\
\hline Control & 8 & 13.38 & 13.648 & 0 & 40 & $t=1.415$ \\
\hline SM & 8 & 9.25 & 4.062 & 2 & 16 & $p=0.194$ \\
\hline SM-L* & 8 & 15.13 & 6.813 & 6 & 24 & \\
\hline
\end{tabular}

Abbreviation: SD, standard deviation.

*Significant at $p<0.05$. 


\section{Discussion}

Orthodontic tooth movement was the result of periodontal tissue remodeling due to mechanical stress on the dental crown. There was an increased distance between the teeth of the marmot (Cavia porcellus) in group 1 compared to that of those in group 3. Bone remodeling occurred due to osteoclast activity within bone resorption in the pressure area, while deposition or bone formation occurred in the tensile with the resulting movement of the tooth. Biologically, fibroblast responses to some cytokines such as IL-1 $\beta$, IL-6, TNF- $\alpha$, and PGE play a role in bone resorption. ${ }^{19}$

Several attempts were made to speed up the bone remodeling process by means of acceleration of the deformation and resorption processes through the administering of prostaglandin and OSC. ${ }^{12,13}$ Other noninvasive methods, for example, ultrasound electrical stimulation and low-irradiation laser therapy (LILT) is used to increase the metabolism of periodontal and bone tissue. The results of the LILT biostimulation and irradiation clinical study indicate a reduction in discomfort and pain, an acceleration of both wound and bone healing, and the effective impeding of inflammatory processes. Clinical trials of LILT use in the orthodontic treatment confirm an acceleration of tooth movement and a reduction in orthodontic treatment time. The effect of LILT irradiation in the orthodontic treatment of mice with an expansion of sutura mediana using orthodontic mechanical pressure compared with LILT intervention showed maxillary bone regeneration ranging between $20 \%$ and $40 \%$. This result is largely determined by the dose, frequency of application, and the treatment. Results of other studies show that molar tooth movement interfered with LILT 30\% faster than without LILT irradiation due to the increased bone remodeling cellular activity. ${ }^{20,21}$

TGF- $\beta 1$ expression increased in the control groups compared with treatment groups 1 and 1 demonstrating that mechanical stress increases TGF- $\beta 1$ expression in the pressure area. The administration of LILT irradiation in group 3 to TGF- $\beta 1$ expression in the pressure area showed significant differences. LILT irradiation may increase activation of TGF- $\beta 1$ in the tension side. TGF- $\beta 1$ expression between groups did not show significant differences. Differences in the increase in TGF- $\beta 1$ expression resulted in tensile and pressure area periodontal ligament fibroblasts in orthodontic tooth movement because TGF- $\beta 1$ is unique among GFs. TGF- $\beta 1$ has various biological activities and bifunctional properties that act as positive and negative regulators in the cell division. TGF- $\beta 1$ stimulates and activates monocytes/macrophages and lymphocytes to eliminate periodontal tissue debris due to the strength of orthodontic mechanical stress. Increased TGF- $\beta 1$ expression was a response to mechanical pressure in orthodontic tooth movement as a potent proinflammatory. TGF- $\beta 1$ recruiting leucocytes at the onset of inflammatory responses, increasing fibroblasts and collagen synthesis proliferation..$^{11,22}$

In this study, LILT intervention in orthodontic tooth movement can stimulate GF such as TGF- $\beta 1$ while inhibiting
B-lymphocyte, T helper, cytotoxic T-lymphocytes, thimocytes, natural killer, lymphokine-activated killer, monocytes, and hematopoietic cell type. In contrast, TGF- $\beta 1$ reacts to stimulants in activating macrophages to secrete multiple GFs in collaboration with IL-2 and IL-5. TGF- $\beta 1$ have important role in controlling IgA secretion by active B-lymphocytes. TGF- $\beta 1$ is the strongest stimulator of bone formation. ${ }^{19,23}$

BMP is one member of the superfamily TGF- 1 substances consisting of BMP-1-7. BMP can induce mesenchymal connective tissue and BMP displays osteoinductive action. BMP performs the same activity as TGF- $\beta 1$ which induces ectopic bone formation if it is in a demineralized bone matrix. The induction continues through granulation, chondrogenesis, osteoid formation, (mineralized bone matrix), and calcification. ${ }^{17,24}$

In this study, an increase in BALP expression occurred in controls $(\mathrm{K})$ compared with groups 2 and 3. Mechanical stress increases BALP expression in pressure areas. The LILT irradiation stimulating BALP expression in the pressure area showed significant differences. LILT irradiation can increase BALP activation in pressure areas. ALP is a protein binding to a synthesized cell membrane in various cells. ALP derived from the osteoblast membrane and subsequently entering the blood circulation plays a role in mineralizing new bone formation. ALP is synthesized and secreted by osteoblasts during the bone formation process observed by histochemistry. ${ }^{16,25}$

BALP is a nonspecific enzyme that affects the capacity to break down phosphate ions from organic substances in organic $\mathrm{pH}$. ALP is an enzyme which functions in mineralization, acting as an ion transport. Increased ALP expression occurred in orthodontic tooth movement on day 14, being more strongly expressed in the tensile area than in the compression area. ${ }^{22,25,26}$

In this study, there were differences in OSC expression between the control groups. The administration of LILT irradiation against OSC expression in the tensile area showed significant differences, but not the pressure area. The function of OSC is associated with bone remodeling, OSC synthesis is increased by $1.25-(\mathrm{OH}) 2 \mathrm{D} 3$ and inhibited by PTH. OSC, also referred to as bone sialoprotein, is a low-molecular weight protein of $5700 \mathrm{Da}$ and the largest noncollagen protein in the bone. The synthesis of these proteins is affected by vitamins $\mathrm{K}$ and $\mathrm{A}$, both of which are involved in gene regulation for OSC synthesis. Originally, OSC was thought to be functioning in bone mineralization. The function of OSC also inhibits excessive mineralization of bone matrix formation. Of the various osteoblast products, OSC is a specific product because it is not synthesized by other tissues. OSC is a marker of bone formation due to osteoblast differentiation. Administration of OSC in mice with orthodontic tooth movement can stimulate osteoclasts in pressure areas to increase osteoclastogenesis during tooth movement. ${ }^{19,27,28}$

\section{Conclusion}

LILT irradiation as adjuvant therapy in orthodontic treatment can improve bone remodeling acceleration in orthodontic 
tooth movement. A combination of mechanical strength forces of $10 \mathrm{~g}$ plus LILT 4 joules irradiation improves the acceleration of alveolar bone remodeling by increasing the expression of TGF- $\beta$, BALP, and OSC.

\section{Financial Support and Sponsorship}

None.

\section{Conflicts of Interest}

None.

\section{Acknowledgment}

The authors would like to thank the Faculty of Dental Medicine, Airlangga University, for the support.

\section{References}

1 Simões RC, Goettems ML, Schuch HS, Torriani DD, Demarco FF. Impact of malocclusion on oral health-related quality of life of 8-12 years old schoolchildren in Southern Brazil. Braz Dent J 2017;28(1):105-112

2 Claudino D, Traebert J. Malocclusion, dental aesthetic selfperception and quality of life in a 18 to 21 year-old population: a cross section study. BMC Oral Health 2013;13:3

3 Scapini A, Feldens CA, Ardenghi TM, Kramer PF. Malocclusion impacts adolescents' oral health-related quality of life. Angle Orthod 2013;83(3):512-518

4 Narayanan RK, Jeseem MT, Kumar TA. Prevalence of malocclusion among 10-12-year-old schoolchildren in Kozhikode district, Kerala: an epidemiological study. Int J Clin Pediatr Dent 2016;9(1):50-55

5 Liu Z, McGrath C, Hägg U. The impact of malocclusion/orthodontic treatment need on the quality of life. A systematic review. Angle Orthod 2009;79(3):585-591

6 Gill DS. Orthodontics at a Glance. 1st ed.: Philadelphia, US: Wiley-Blackwell; 2008:1-14

7 Aftitah VB. Relationship between Malocclusion with Adolescence Quality of Life at Dental Hospital Hasanuddin University Makassar [dissertation]. Makassar, Indonesia: 2015.

8 Kusuma ARP. Mouth Breathing as risk factor and etiology of malocclusion. Majalah Ilmiah Sultan Agung. 2010; 48(123):1-19. Available at http://jurnal.unissula.ac.id/index.php/majalahilmiah sultanagung/article/view/23/19

9 Joelijanto R. Oral habits that cause malocclusion. Insiciva Dent J 2012;1(2):87-94. Available at http://journal.umy.ac.id/index. $\mathrm{php} / \mathrm{di} /$ article/view/536

10 Proffit W, Fields H, Sarver D. Contemporary Orthodontics. 6th ed. Amsterdam, The Netherlands, US: Elsevier; 2007: 50-100

11 Huang H, Williams RC, Kyrkanides S. Accelerated orthodontic tooth movement: molecular mechanisms. Am J Orthod Dentofacial Orthop 2014;146(5):620-632

12 Yamasaki K. The role of cyclic AMP, calcium, and prostaglandins in the induction of osteoclastic bone resorption associated with experimental tooth movement. J Dent Res 1983;62(8):877-881
13 Takano-Yamamoto T, Kawakami M, Kobayashi Y, Yamashiro T, Sakuda M. The effect of local application of 1,25-dihydroxycholecalciferol on osteoclast numbers in orthodontically treated rats. J Dent Res 1992;71(1):53-59

14 Tyrovola JB, Perrea D, Halazonetis DJ, Dontas I, Vlachos IS, Makou M. Relation of soluble RANKL and osteoprotegerin levels in blood and gingival crevicular fluid to the degree of root resorption after orthodontic tooth movement. J Oral Sci 2010;52(2):299-311

15 Baeza M, Garrido M, Hernández-Ríos P, et al. Diagnostic accuracy for apical and chronic periodontitis biomarkers in gingival crevicular fluid: an exploratory study. J Clin Periodontol 2016;43(1):34-45

16 Golub EE, Boesze-Battaglia K. The role of alkaline phosphatase in mineralization. Curr Opin Orthop 2007;18:444-448

17 Hankenson KD, Gagne K, Shaughnessy M. Extracellular signaling molecules to promote fracture healing and bone regeneration. Adv Drug Deliv Rev 2015;94:3-12

18 El Gazaerly H, Elbardisey DM, Eltokhy HM, Teaama D. Effect of transforming growth factor Beta 1 on wound healing in induced diabetic rats. Int J Health Sci (Qassim) 2013;7(2):160-172

19 Ganesh ML, Saravana Pandian K. Acceleration of tooth movement during orthodontic treatment - A frontier in orthodontics. J Pharm Sci Res 2017;9(5):741-744

20 Sousa MV, Scanavini MA, Sannomiya EK, Velasco LG, Angelieri F. Influence of low-level laser on the speed of orthodontic movement. Photomed Laser Surg 2011;29(3): 191-196

21 Doshi-Mehta G, Bhad-Patil WA. Efficacy of low-intensity laser therapy in reducing treatment time and orthodontic pain: a clinical investigation. Am J Orthod Dentofacial Orthop 2012;141(3):289-297

22 Genc G, Kocadereli I, Tasar F, Kilinc K, El S, Sarkarati B. Effect of low-level laser therapy (LLLT) on orthodontic tooth movement. Lasers Med Sci 2013;28(1):41-47

23 Kasai K, Yuching Chou M, Yamaguchi M. Molecular effects of low-energy laser irradiation during orthodontic tooth movement. Semin Orthod 2015;21(3):203-209

24 Rutkovskiy A, Stensløkken KO, Vaage IJ. Osteoblast differentiation at a glance. Med Sci Monit Basic Res 2016;22: 95-106

25 Halling Linder C, Ek-Rylander B, Krumpel M, et al. Bone alkaline phosphatase and tartrate-resistant acid phosphatase: potential co-regulators of bone mineralization. Calcif Tissue Int 2017;101(1):92-101

26 Chamieh F, Collignon AM, Coyac BR, et al. Accelerated craniofacial bone regeneration through dense collagen gel scaffolds seeded with dental pulp stem cells. Sci Rep 2016;6: 38814

27 Hashimoto F, Kobayashi Y, Mataki S, Kobayashi K, Kato Y, Sakai H. Administration of osteocalcin accelerates orthodontic tooth movement induced by a closed coil spring in rats. Eur J Orthod 2001;23(5):535-545

28 Dalaie K, Hamedi R, Kharazifard MJ, Mahdian M, Bayat M. Effect of low-level laser therapy on orthodontic tooth movement: a clinical investigation. J Dent (Tehran) 2015;12(4):249-256 